\title{
O Sistema de Avaliação Externa dos Padrões de Qualidade da Educação Superior no Brasil: considerações sobre os indicadores
}

\author{
PAULO SÉRGIO MARCHELLI \\ Professor Doutor da Universidade São Marcos, São Paulo \\ paulo.marchelli@ajato.com.br
}

\begin{abstract}
Resumo
Este trabalho aborda o Sistema Nacional de Avaliação da Educação Superior (Sinaes), e analisa as diretrizes conceituais e o instrumento metodológico utilizados para avaliação externa. O método de análise corresponde ao estabelecimento de comparações entre o sistema adotado pelo Brasil e por outros países cujos padrões de qualidade em educação superior são internacionalmente reconhecidos. É enfocada a estrutura da matriz das dimensões de avaliação externa do Sinaes, detalhando-se os critérios utilizados para a atribuição de conceitos aos indicadores da Titulação, Regime de Trabalho e Publicações do Corpo Docente. Como principal conclusão, o estudo apresenta as razões pelas quais os referidos critérios precisam ser reconsiderados, mostrando seus pontos falhos e apontando caminhos para seu aperfeiçoamento.
\end{abstract}

Palavras-chave: avaliação da educação superior, políticas de qualidade, indicadores de avaliação.

\section{Resumen}

Este artículo aborda el Sistema Nacional de Evaluación de la Educación Superior (Sinaes) analizando las directrices conceptuales y el método empleado para la evaluación exterior. El método de análisis consiste en establecer comparaciones entre el sistema adoptado por Brasil y por otros países en los cuales los patrones de calidad en la educación superior son reconocidos internacionalmente. El foco está puesto en la estructura de la matriz de las dimensiones de la evaluación externa del Sinaes, buscando detallar los criterios empleados para la atribución de valores para indicadores como títulos, régimen de trabajo y publicaciones del cuerpo docente. Como principal conclusión, el trabajo expone las razones por las cuales los referidos criterios precisan ser reconsiderados, mostrando sus errores y señalando caminos para su perfeccionamiento.

Palabras-clave: evaluación de la educación superior, políticas de calidad, indicadores de evaluación.

\begin{abstract}
This paper is about the National Evaluation System of Higher Education - Sinaes - as it is called in Brazil. It analyzes conceptual lines of direction and the methodological instrument used for external evaluation. The method of analysis is based on comparisons between the system adopted in Brazil and other countries whose standards of quality in higher
\end{abstract}


education are internationally recognized. The matrix structure of the dimensions for external evaluation of the National Evaluation System of Higher Education - Sinaes - is examined, highlighting details of the criteria used for giving grades to the Teaching Staff's Titles, Working Hours and Publications indicators. As its major conclusion, the study lists the reasons why the above criteria need to be reconsidered by pointing out their flaws and suggesting ways for their improvement.

Key-words: higher education evaluation, quality policy, evaluation indicators. 


\section{INTRODUÇÃO}

Cada país adotou, ao longo das últimas décadas, uma metodologia própria de avaliação do seu sistema de ensino superior, podendo ser destacados os recentes trabalhos que descrevem o caso da Inglaterra (Harvey, 2005), Malásia (Alfan, Othman, 2005), Japão (Nguyen, Yoshinari, Shigeji, 2005), Região Administrativa Especial da China de Hong Kong (Mok, 2005), Índia (Stella, 2004), Chile (Lemaitre, 2004), Hungria (Rozsnyai, 2004) e África do Sul (Strydom, Strydom, 2004).

No Brasil, os debates políticos em torno do funcionamento da educação superior vem ocorrendo desde o fim dos anos 1950 e início dos anos 1960, época em que as características da prática democrático-populista do regime vigente abriram intensos questionamentos sobre o projeto da universidade (Sguissardi, 1997), surgindo propostas para que processos de melhoria do ensino fossem prioritariamente desencadeados (Grego, Souza, 2004).

Com a instalação do governo militar em 1964, as políticas para a educação superior visaram a garantir a inserção do Brasil na funcionalidade múltipla do capitalismo dependente, de forma que o impacto de um panorama econômico internacional restritivo acirrou a crise educacional com greves de estudantes e serviu de justificativa para uma série de acordos do Brasil com a Agency for International Development (AID). Para Romanelli (1978), por meio desse acordo, denominado MEC/USAID, o país entregou a organização do sistema educacional superior aos técnicos estrangeiros. Em 1968, houve o acirramento do regime militar e foram produzidos dois documentos importantes como marcas da reforma do ensino superior: o Plano Atcon e o Relatório da Comissão Meira Mattos (Amorim, 1991). As questões de avaliação do Plano Atcon fundamentavamse em duas dimensões: a primeira evocava os princípios idealizadores de um modelo empresarial para o sistema universitário; e, a segunda, projetava autonomia e independência para este sistema. Mas, para que essa autonomia se concretiza-se, as instituições teriam que ser transformadas em fundações privadas. O Relatório da Comissão Meira Mattos trazia uma ampla avaliação da situação política, social e econômica do País, apresentando medidas para atender aos reclamos sociais de acesso à universidade, reprimindo a insatisfação de intelectuais e estudantes. Com base no conceito de rentabilidade do sistema educacional, o Relatório propunha uma ampla reestruturação institucional, visando à obtenção de maior desempenho da rede escolar com menor aplicação de recursos. Ainda nessa época, o Departamento de Assuntos Universitários do Ministério da Educação (MEC), hoje Secretaria da Educação Superior 
(SESu), iniciou a publicação de relatórios anuais que forneciam dados relativos à situação do ensino superior e apresentavam instrumentos de análise que se esperava viessem a ser utilizados na avaliação de desempenho e no desenvolvimento de cada instituição do sistema como um todo (Neiva, 1988).

Os primeiros textos especificamente elaborados sobre a temática da avaliação revelam uma preocupação exaustiva com o controle da qualidade das Instituições de Educação Superior (IES), tendo em vista a hipótese de que o seu crescimento exacerbado e o grande número de matrículas recebidas incorriam em perda de qualidade. Os problemas que surgiram com a expansão da educação básica, na década dos anos 1960, foram prioritários para se pensar sobre a criação acelerada de IES, que nas décadas dos anos 1980 e 1990 atingiria altos patamares quantitativos. Como o modelo privado de expansão do ensino superior custava caro ao cidadão, sua avaliação qualitativa, mais do que nunca, era importante como forma de prestação de contas pelo setor público à sociedade. Dessa forma, as assertivas sobre os benefícios políticos decorrentes da criação e do aperfeiçoamento dos instrumentos de aferição da qualidade de ensino, constituíram-se como verdadeiros princípios institucionais da democracia brasileira pós-regime militar.

O primeiro programa submetido à discussão política e aprovado no país surgiu em 1983, com o nome de Programa de Avaliação da Reforma Universitária (Paru), apresentado pelo MEC em decorrência das discussões havidas no âmbito do então Conselho Federal de Educação (CFE), envolvendo as greves ocorridas nas universidades federais nos anos anteriores (Cunha, 1997). A formulação do Paru sofreu a influência do setor de pós-graduação, que no início da década de 80 contava com um sistema de avaliação de amplo reconhecimento pela sua qualidade. A graduação não dispunha de nada comparável e necessitava de um mecanismo que pudesse apontar em que medida a Reforma Universitária realmente se efetivou, quais as vantagens alcançadas e os problemas enfrentados pelos diversos tipos de cursos e instituições (Dias, 2001, p. 71).

A metodologia de avaliação consistiu na aplicação de questionários aos docentes, dirigentes universitários e estudantes, visando a coletar dados sobre a estrutura didática e administrativa das IES, bem como sobre a forma de atendimento à expansão das matrículas e os meios utilizados para avaliação das atividades de ensino, pesquisa e extensão. A análise de dados priorizou quantificar a qualidade do corpo docente, discente e técnico-administrativo, a produtividade científica e a vinculação da instituição com a comunidade. 
Gonçalves Filho (2004) aponta que os enfoques avaliativos, surgidos nos EUA com base no funcionalismo neoliberal, influenciaram o Brasil na concepção do Paru. As premissas de tais enfoques estavam associadas às crenças advindas das novas concepções de democracia. As pesquisas sobre aprendizagem de programas ou de sistemas já ocorriam de forma pontuada no Brasil desde os anos de 1970. Apesar de se intensificarem nos anos 1990, essas pesquisas caracterizaram-se, em geral, por serem ainda fragmentárias. Embora muitos esforços tenham sido feitos para o enfrentamento desta situação, a experiência brasileira em avaliação nunca deixou de ser influenciada pela literatura norte-americana. Os autores norte-americanos inspiraram as pesquisas em quase todos os países do mundo ocidental e computam hoje mais de meio século de teorias e práticas nessa área. Nos EUA, a origem das avaliações em grande escala, no âmbito do Estado, deu-se no pós II Guerra Mundial e foram concomitantes ao processo de construção do Estado de Bem Estar. Vianna (2002) e Leite (1997) destacam a pertinência das iniciativas de avaliação do ensino superior voltadas para o rendimento do aluno. Segundo esses autores, o ano de 1977 marcou o início das avaliações da pós-graduação brasileira pela Capes, que influenciou os sistemas de avaliação da graduação.

\section{OS DEBATES DA NOVA REPÚBLICA (1985-1990)}

Um ano depois de iniciado, no entanto, o Paru foi desativado sem que se tivesse chegado a um consenso sobre os dados recolhidos. O MEC, a quem competia fazer a Reforma Universitária, na ausência desse consenso, viu-se tomado por intensas disputas pelo poder interno, tendo-se abrigado no seu interior vários grupos políticos diferentes que reivindicavam para si a competência de decidir o que o país deveria fazer com as suas universidades.

Em 1985, durante o governo José Sarney, Marco Maciel foi nomeado ministro da Educação, criando a Comissão Nacional para a Reformulação do Ensino Superior, com 24 membros. No relatório produzido por essa Comissão (Brasil, 1985), a questão da avaliação da qualidade institucional extensível a toda a comunidade universitária aparece pela primeira vez, mostrando que o país ainda estava longe de formular um instrumento político que agradasse a todos os setores nacionais. A heterogeneidade dos membros da Comissão era marcante e nem todos tinham vivência universitária, propiciando grande confusão, de forma que o produto de seu trabalho foi um relatório difuso, constituído por um conjunto de textos desconexos a propósito de questões desencontradas. A comunidade 
acadêmica entrincheirou-se para evitar mudanças inapropriadas na universidade e o conceito de autonomia foi o tom normativo do próprio documento. A comissão criada por Sarney não suscitou nenhuma ação política direta por parte do governo.

No fim de 1985, poucos meses depois de concluir o relatório, a Comissão Nacional para a Reformulação do Ensino Superior foi destituída e, no início de 1986, Marco Maciel criou o Grupo Executivo para Reformulação da Educação Superior (Geres), que contava com cinco membros: um professor, um representante do MEC, um ex-reitor, um pesquisador e o diretor da Coordenadoria de Aperfeiçoamento do Pessoal do Ensino Superior (Capes). Essa última havia desenvolvido diversos instrumentos específicos para avaliação dos cursos e programas de pósgraduação, de forma que o Geres planejava se valer dessa experiência.

$\mathrm{O}$ Geres elaborou um anteprojeto de lei que propunha uma reformulação no funcionamento do sistema constituído pelas IES federais. Entretanto, diante do grande número de críticas recebidas, advindas principalmente pelo receio da desobrigação do governo para com o suprimento de recursos financeiros, o Presidente da República, no contexto das dificuldades políticas existentes em pleno período constituinte, retirou o anteprojeto de lei do Congresso e reeditou-o como apenas uma orientação para a formulação das políticas gerais do governo para o ensino superior.

Ainda assim, o Geres acirrou os debates entre as universidades e o governo, ao estabelecer novos critérios de avaliação para fundamentar o credenciamento e o recredenciamento de IES. Nesses debates, a polêmica centrou-se principalmente nas articulações estabelecidas entre os conceitos de autonomia e de avaliação. Os critérios apresentados pretendiam avaliar a responsabilidade social das instituições e, ao mesmo tempo, dar a elas maior autonomia, inclusive financeira. $\mathrm{O}$ Geres reproduzia a palavra de ordem efetuada pelos organismos financeiros internacionais, porta-vozes da emergente economia neoliberal restritiva, sobretudo o Banco Mundial, propondo a redução dos investimentos públicos na educação. O tema e $O$ interesse da avaliação adquiriu muito mais força a partir do momento em que se tornou, em todo o mundo, mais aguda a crise que tem levado os governos a investirem cada vez menos na área social, especialmente em educação (Sobrinho, 1996, p. 20).

Depois das atribulações e desencontros iniciais, no fim da década de 80, a avaliação do ensino superior se insere finalmente como instrumento de ação política do Estado, refletindo o momento internacional em relação às instituições educacionais como um todo. Em 1987, isso começa a ficar mais evidente, quando foi realizado, em Brasília, o Encontro Internacional de Avaliação do Ensino Superior (Encontro, 1988), promovido para discutir 
e analisar os modelos implantados em outros países, principalmente Canadá, França, Inglaterra e Japão. As conclusões desse importante evento internacional podem ser resumidas em oito pontos principais: 1) a avaliação do ensino superior brasileiro é considerada uma providência inadiável, e procedimentos urgentes deveriam ser adotados para efetivá-la; 2) a avaliação deverá ter por objetivo inicial cada um dos cursos de graduação, cabendo às universidades a definição das áreas prioritárias e a fixação de critérios indicadores de qualidade; 3) o MEC deverá promover e estimular o processo de avaliação interna e de avaliação interpares externa; 4) a avaliação do ensino tem como conseqüência a busca da qualidade nas atividades acadêmicas afins, como a pesquisa e a extensão; 5) os indicadores de avaliação devem ser adequados às especificidades de cada instituição e às diferentes áreas de conhecimento; 6) os resultados devem ser divulgados e publicados para amplo conhecimento da sociedade; 7) a avaliação deverá revestir-se de elevado grau de seriedade e correção para corresponder a níveis desejáveis de eficácia; e 8) o governo deverá destinar recursos específicos, por intermédio do MEC, para apoiar os projetos de avaliação das universidades públicas.

Em 1988, quatro outros grandes encontros deram continuidade ao processo iniciado pelo Geres, realizados com apoio financeiro do MEC/SESu dentro do seguinte cronograma: em março, na Universidade Federal do Pará com participação de IES da Amazônia e do Pará; em maio, na Universidade Federal de Santa Catarina, reunindo instituições do Sul; ainda em maio, na Universidade Federal do Ceará, envolvendo as instituições isoladas do Nordeste; e, em setembro, na Universidade Estadual Paulista, de caráter mais regional, mas contando com a presença de participantes de outros Estados. Esses encontros versavam sobre a necessidade de implantação da avaliação, não aparecendo ainda preocupações com a elaboração de indicadores quantitativos ou de desempenho (Silva, Lourenço, 1998).

Ainda que tímidos, os passos até então ensaiados para a consolidação das políticas de avaliação das instituições de ensino superior tiraram o país do atraso internacional, pois isso já fazia parte das estratégias para o desenvolvimento econômico e social de grande parte das outras nações, desde o fim dos anos 70. Os casos mais visíveis, na década de 1980, eram o Chile na América Latina e o Reino Unido de Margareth Tatcher, então na liderança das políticas neoliberais (Sobrinho, 1998). Em 1987, a Universidade de Brasília (UnB) começou a organizar seu processo interno de auto-avaliação, seguida em 1988 pela Universidade Federal do Paraná (UFPR) e, no mesmo ano, pela Universidade de São Paulo (USP). Em 1991, 
foi a vez da Universidade Estadual de Campinas (Unicamp) realizar sua auto-avaliação.

\section{A HEGEMONIA DAS POLÍTICAS NEOLIBERAIS DOS ANOS 1990 E AS PRÁTICAS AVALIATIVAS}

O modelo de avaliação desenvolvido nos anos 1990, conduzido pelos agentes internacionais de suporte financeiro, notadamente o Banco Mundial, que elaborou propostas compreendendo a avaliação do ensino como parte das estratégias que seriam aplicadas para a concessão de financiamentos, provocou forte impacto sobre a universidade pública no Brasil, que precisava ser reorganizada para contribuir com o tributo de diminuir os custos estatais, precisando ser mais autônoma e pactuar com as forças do mercado, produzindo conhecimentos úteis e rentáveis como condição de sobrevivência na competitiva sociedade global. A avaliação era vista como instrumento de medida e controle para responder às expectativas de eficiência e produtividade no ensino superior, massificado pela explosão das matrículas e compelido a se tornar mais produtivo em situações de crescentes restrições orçamentárias. Em 1994, o Banco Mundial propôs resumidamente as seguintes diretrizes como condição de financiamento para a educação superior:

[...] incentivar a diversidade das instituições educacionais superiores e a competitividade (não a solidariedade) entre elas; estimular a ampliação e a expansão de instituições privadas; levar as universidades públicas a produzirem cada vez mais sua sobrevivência pela venda de serviços e cobrança de taxas de alunos; e, vincular os financiamentos dos organismos oficiais a critérios de eficiência e produtividade em termos mercadológicos. (Sobrinho, 1996, p. 16)

Em julho de 1993, a Secretaria de Educação Superior do Ministério da Educação e do Desporto (SESu) criou a Comissão Nacional de Avaliação das Universidades Brasileiras, com a função de implementar os processos políticos recomendados internacionalmente. Esta comissão era coordenada pelo Departamento de Política do Ensino Superior da SESu e reunia vários segmentos: Associação Nacional dos Dirigentes das Instituições Federais de Ensino Superior (Andifes), Associação Brasileira das Universidades Estaduais e Municipais (Abruem), Associação Nacional das Universidades Particulares (Anup), Associação Brasileira das Escolas Católicas (Abesc), Fóruns Nacionais de Pró-Reitores de Graduação, Pesquisa e PósGraduação, e Fóruns Nacionais de Pró-Reitores de Planejamento, Administração, e Extensão. Após a instalação da Comissão, foi constituído 
um Comitê Técnico Assessor composto por especialistas, com a função de analisar os projetos oriundos das universidades. A posição do MEC neste processo seria de coordenador, articulador e agente financiador da avaliação institucional, assumindo a postura política de trabalhar em parceria com as universidades.

Nesse contexto, surge o Programa de Avaliação Institucional das Universidades Brasileiras (Paiub), concebendo a auto-avaliação como etapa inicial de um processo que se estenderia a toda as instituições e se completaria com a avaliação externa. O princípio básico do Paiub encontrase na globalidade com que as IES deveriam ser avaliadas, de forma que todos os elementos - ensino, pesquisa, extensão, qualidade das aulas, laboratórios, titulação dos docentes, serviços, etc. - que compõem a vida universitária deveriam fazer parte da avaliação, para que a mesma seja a mais completa possível (Dias, 2001, p. 79). Além disso, o Paiub partiu em busca de uma linguagem comum para todas as IES do país, por meio da criação de uma tabela mínima de indicadores institucionais para o ensino de graduação. Destacam-se também as seguintes idéias presentes nos subsídios que sustentaram o programa: respeito à identidade institucional, de forma a levar em consideração as diferenças entre as IES avaliadas; não punição ou premiação pelos resultados alcançados; adesão voluntária; busca de legitimidade ética do processo; e continuidade das ações avaliativas com vistas a integrá-las à cultura institucional.

O Paiub pretendeu estabelecer novas formas de diálogo entre o governo e a comunidade acadêmica, buscando legitimar a cultura da avaliação e promover mudanças visíveis na dinâmica de ensino. Embora tenha recebido ampla adesão das universidades, sua implementação foi afetada pela interrupção do apoio do MEC, fazendo com que se reduzisse aos programas de subsídios para dar andamento somente aos objetivos da auto-avaliação interna. Dessa forma, o programa chegou a uma encruzilhada e em 10 de outubro de 1996 o MEC publicou o Decreto $n^{\circ}$ 2.026 (Brasil, 1996), estabelecendo novos procedimentos para o processo de avaliação dos cursos e instituições de ensino superior. A conclusão a que se chega é que o Paiub não conseguiu cumprir, em sua curta existência, o objetivo de servir como instrumento efetivo de medida sobre a produtividade do ensino superior brasileiro, de modo a atender às exigências impostas pelas políticas neoliberais hegemônicas de competitividade e eficiência mercadológica, preconizadas pelos agentes internacionais de suporte financeiro, como o Banco Mundial.

O ponto central do novo Decreto estabelecido após o Paiub foi a análise dos principais indicadores de desempenho global do sistema nacional de ensino superior, por região e unidade da federação, segundo as áreas do 
conhecimento e o tipo ou a natureza das instituições de ensino (Art. $1^{\circ}$, inciso I). Essa análise seria feita pela Secretaria de Avaliação de Informação Educacional do MEC (SEDIAE), abrangendo os seguintes pontos:

I - taxas de escolarização bruta e líquida; II - taxas de disponibilidade e de utilização de vagas para ingresso; III - taxas de evasão e de produtividade; IV tempo médio para conclusão dos cursos; $V$ - indices de qualificação do corpo docente; VI - relação media alunos por docente; VII - tamanho médio das turmas; VIII - participação da despesa com ensino superior nas despesas públicas com educação; IX - despesas públicas por aluno no ensino superior público; X - despesa por aluno em relação ao Produto Interno Bruto - PIB por habitante nos sistemas público e privado; e, XI - proporção da despesa pública com a remuneração de professores. (Brasil, 1996, Art. $3^{\circ}$ )

No Decreto, o parágrafo único do Art. $4^{\circ}$ estabelecia que cada instituição deveria apresentar às comissões de avaliação externa dados obtidos por meio de um processo de avaliação interna. Esses dados, no entanto, ficaram longe de ser produzidos, pois a cultura necessária para obtê-los não existia no país. Dizia o Decreto que: a avaliação dos cursos de graduação far-se-á pela análise de indicadores estabelecidos pelas comissões de especialistas de ensino [...] (Art. $5^{\circ}$ ). No entanto, na prática, o trabalho dos especialistas consistiu apenas na aplicação da famosa escala de 5 níveis que vai do muito fraco ao muito bom. Tratava-se, portanto, de uma avaliação subjetiva, de fundo meramente qualitativo, longe de representar a objetividade contida em indicadores definidos por estatísticas nacionais precisas. Questões como essa mostram que a avaliação do ensino superior brasileiro, no início dos anos 1990, estava longe de atingir patamares mínimos de objetividade.

Uma recomendação interessante é a que segue:

A avaliação dos cursos de graduação conduzida pelas Comissões de Especialistas, designadas pela SESu, será precedida de análise abrangente da situação da respectiva área de atuação acadêmica ou profissional, quanto ao domínio do estado da arte na área, levando em consideração o contexto internacional, e o comportamento do mercado de trabalho nacional. (Brasil 1996, Art. $5^{\circ}$ )

Numa situação em que os mercados de trabalho nacional e internacional passavam por profundas transformações estruturais, decorrentes de uma economia em completa mudança, pergunta-se: como saber se o acadêmico, de determinado curso de uma certa instituição, estava recebendo o ensino correto para obter uma formação profissional adequada para atuar num mercado de trabalho de futuro incerto? Se até a pergunta é difícil de ser feita, imagine a resposta do avaliador! 
Quanto à análise das condições de oferta pelas instituições de ensino superior, serão consideradas:

[...] I. a organização didático-pedagógica; II. a adequação das instalações físicas em geral; III. a adequação das instalações especiais, tais como laboratórios, oficinas e outros ambientes indispensáveis à execução do currículo; IV. a qualificação do corpo docente; $V$. as bibliotecas com atenção para o acervo bibliográfico, inclusive livros e periódicos, regime de funcionamento, modernização dos serviços e adequação ambiental. (Brasil 1996, Art. $6^{\circ}$ )

De todos esses indicadores, a qualidade do corpo docente, que recebeu depois o nome de Índice de Qualificação do Corpo Docente (IQCD), acabou assumindo importância fundamental, incorporando-se à matriz sistêmica de avaliação que veio a seguir. Uma contribuição importante no que diz respeito à organização do trabalho docente no Brasil é que, na segunda metade dos anos 90, o Exame Nacional de Cursos (ENC), que funcionou de 1996 a 2003, mostrou que não havia nenhuma correlação direta entre o IQCD de uma instituição e o rendimento de seus alunos, ou seja, alunos oriundos de uma instituição com IQCD mais alto podem ir pior nas provas do que os provindos de outra com IQCD mais baixo e viceversa. $\mathrm{O}$ fator que se mostrou diretamente associado ao rendimento do aluno está situado na forma como as instituições estruturam a carreira docente. Assim, os dados do ENC apontam que a valorização do trabalho do professor, por meio da organização de carreiras docentes consistentes e o bom gerenciamento das horas disponíveis, tende a produzir um melhor desempenho pelos alunos. A qualificação do professor, na verdade, deve ser entendida apenas como condição de acesso à carreira e progressão dentro dela, mas se essa não for adequada para produzir bons resultados, os talentos de um corpo docente otimamente qualificado poderão estar sendo jogados fora.

\section{FUNDAMENTOS DO SISTEMA DE AVALIAÇÃO CONTEMPORÂNEO AOS ANOS 2000}

O balanço da década de 1990 aponta que os instrumentos avaliativos aplicados posicionaram-se estrategicamente em relação à dinâmica organizacional e estabeleceram novos padrões de funcionalidade para o sistema de ensino superior brasileiro. A expansão do sistema, mormente no que diz respeito ao aumento do número de cursos oferecidos, que se concentrou em grande parte nas instituições privadas, potencializou 
a necessidade de avaliação e definiu a estrutura dos instrumentos concebidos para isso.

Como a massificação do sistema de ensino tem sido um dos objetivos centrais da política oficial para o ensino superior, tal massificação foi promovida a partir da montagem de procedimentos de avaliação que têm por objetivo gerar, por um lado, informações específicas sobre o desempenho das instituições, para reestruturar e promover o mercado da educação superior, por meio da competição institucional pelos estudantes e do fortalecimento do poder dos estudantes-consumidores, que passam por sua vez a competir pelas instituições melhores avaliadas, a partir das informações produzidas pelo Exame Nacional de Cursos; por outro lado, o estabelecimento dos procedimentos de avaliação tinha por objetivo desafiar o abuso da desqualificação da maioria das instituições de ensino superior, particularmente no setor privado, predominantemente por intermédio da Avaliação das Condições de Oferta de Cursos de graduação. (Gomes, 2002, p. 284)

Em 2001, foi editado o Plano Nacional de Educação - PNE (Brasil, 2001a), contemplando a idéia de instituir um amplo sistema de metas para a educação superior, e estabelecendo que até o ano de 2010 será provida a oferta de vagas para, pelo menos, $30 \%$ da população na faixa etária de 18 a 24 anos. De fato, a taxa acumulada do crescimento geral das matrículas no período 1996-1999 foi de 34,7\%, enquanto no período 2000-2003 atingiu $64,1 \%$. Grande parte da expansão foi realizada dentro do setor privado, que absorveu $45,2 \%$ no primeiro quadriênio indicado e $78,9 \%$ no segundo. Já o setor público apresentou resultados bem mais modestos, absorvendo 18,8\% e $36,9 \%$, respectivamente. A taxa média de crescimento das matrículas como um todo foi de $7,7 \%$ e $13,1 \%$, respectivamente. Com base nesse último resultado, projeta-se que até o ano 2010 haja 9.234 .548 alunos matriculados no ensino superior, devendo, por força do PNE, a oferta pública cobrir pelo menos $40 \%$ das vagas, correspondente a 3.693 .820 alunos (Brasil, 2004).

Seis meses após a promulgação da lei que editou o PNE, foi baixado um decreto que estabeleceu novos procedimentos operacionais de avaliação (Brasil, 2001b), corrigindo várias dificuldades presentes no decreto anterior (Brasil, 1996), que foi revogado. Nos novos procedimentos operacionais estabelecidos, foram eliminados os indicadores de desempenho global do sistema, que, como já se demonstrou, pouco tinham a ver com as instituições vistas isoladamente: taxas de escolarização bruta e líquida, taxas de disponibilidade e de utilização de vagas para ingresso etc. No tocante à avaliação do desempenho individual das instituições, foram mantidos praticamente todos os indicadores já utilizados e acrescidos os seguintes: capacidade de acesso a redes de comunicação e sistemas de informação (Brasil, 2001b, Capítulo IV, Art. 17, Inciso II, item d); e, a auto-avaliação 
realizada pela instituição $e$ as providências adotadas para saneamento de deficiências identificadas (item j). No tocante à análise das condições de oferta, foram mantidos os indicadores sobre a organização didáticopedagógica, adequação das instalações físicas gerais e específicas, adequação das bibliotecas e qualidade do corpo docente. Com relação a esse último, a nova legislação incluiu os seguintes aspectos que não eram contemplados anteriormente: a experiência profissional, a estrutura da carreira, a jornada de trabalho e as condições de trabalho (Brasil, 2001b, Cap. IV, Art. 17, Parágrafo $1^{\circ}$, Inciso II). No inciso sobre as bibliotecas também foram incluídos novos aspectos: atenção especial para com o acervo especializado, inclusive o eletrônico, para as condições de acesso às redes de comunicação e para os sistemas de informação, regime de funcionamento e modernização dos meios de atendimento (Inciso IV).

$\mathrm{O}$ único ponto realmente significativo que o novo sistema acrescenta ao modelo anteriormente vigente diz respeito ao corpo docente. O ENC já havia demonstrado que o IQCD não é suficiente para abalizar a qualidade da oferta de ensino, sendo prioritário o levantamento de outros aspectos, como a estrutura da carreira, a jornada a as condições de trabalho, agora finalmente contemplados.

A nova questão sobre a capacidade de acesso às redes de comunicação e sistemas de informação, bem como sobre o acervo eletrônico das bibliotecas etc., mesmo que constitua uma novidade, não é significativa. Na verdade, o indicador está mal definido, pois a capacidade de acessar os sistemas é bem diferente da disponibilidade dos sistemas para acesso. Essa última parece ser a que o decreto estabelece que seja medida, o que remonta ao mesmo problema da década passada, quando a informatização do ensino não produziu de fato nenhum resultado qualitativo. A avaliação da capacidade de acesso às redes de comunicação e aos sistemas de informação necessita, portanto, ser avaliada em termos de indicadores que apontem para o uso dos recursos existentes e não apenas para a velocidade de conexão dos computadores com a Internet, o desempenho dos equipamentos, o tamanho da rede formada etc.

Em 2003, foi instituída a Comissão Especial de Avaliação da Educação Superior (CEA), que elaborou uma revisão crítica dos instrumentos, metodologias e critérios até então utilizados e sugeriu reformulações com base na construção de um sistema capaz de aprofundar os compromissos e as responsabilidades sociais das instituições. A CEA realizou audiências públicas com entidades representativas de vários setores sociais e propôs o Sistema Nacional de Avaliação da Educação Superior (Sinaes), redigindo um documento cujo objetivo foi estabelecer princípios com base no conceito de que, fundamentalmente, é a função 
social das IES que deve ser destacada como medida de sua eficiência. Surgiu, dessa forma, uma nova metodologia de avaliação do ensino superior, aperfeiçoando os procedimentos e os instrumentos de avaliação até então utilizados.

Em 14 de abril de 2004, entra em vigor a Lei n. 10.861 (Brasil, 2004a), que institui o Sinaes com a finalidade de assegurar o processo nacional de avaliação das instituições de educação superior, dos cursos de graduação e do desempenho acadêmico de seus estudantes (Art. $1^{\circ}$ ). O Sinaes é estabelecido, dessa forma, por três subsistemas integrados: 1) a avaliação institucional, que será realizada em duas instâncias, interna e externa, e terá como objetivo identificar o seu perfil [das instituições] e o significado de sua atuação, por meio de suas atividades, cursos, programas, projetos e setores, considerando as diferentes dimensões institucionais [...] (Art. $\left.3^{\circ}\right) ; 2$ ) a avaliação dos cursos de graduação, destinada a identificar as condições de ensino oferecidas aos estudantes, em especial as relativas ao perfil do corpo docente, às instalações físicas e à organização didático-pedagógica (Art. $4^{\circ}$ ); e 3) a avaliação dos alunos, que será realizada mediante aplicação do Exame Nacional de Desempenho dos Estudantes - Enade (Art. $5^{\circ}$ ) e terá como função aferir o domínio dos estudantes sobre os conteúdos programáticos previstos nas diretrizes curriculares do respectivo curso de graduação, suas habilidades para ajustamento às exigências decorrentes da evolução do conhecimento e suas competências para compreender temas exteriores ao âmbito específico de sua profissão [...] (Art. $5^{\circ}, \S 1^{\circ}$ ). No dia 9 de julho de 2004, o Sinaes foi regulamentado pela Portaria n. 2.051 (Brasil, 2004b).

\section{A OPERACIONALIZAÇÃO DO SINAES}

O sistema de avaliação externa implantado pelo Sinaes vale-se de uma ampla gama de indicadores, ordenados dentro de dez categorias analíticas distintas, denominadas dimensões, por meio das quais se procura construir uma estrutura orgânica que abrange todas as atividades finalísticas e todos os procedimentos organizativos e operacionais das instituições (Brasil, 2005). Desse modo, as dimensões são agrupamentos de grandes traços ou características sobre os quais se emite juízo de valor para exprimir a totalidade da qualidade institucional. A estas são atribuídos pesos relativos à sua importância diante dos objetivos regulatórios e formativos assumidos pelo processo de avaliação, conforme destacado no quadro 1. 


\section{Quadro 1 - Dimensões da avaliação externa do Sinaes e seus respectivos pesos relativos}

\begin{tabular}{|c|l|c|}
\hline Dimensão & \multicolumn{1}{|c|}{ Instrumento } & $\begin{array}{c}\text { Peso } \\
\text { Relativo }\end{array}$ \\
\hline 1 & Missão e Plano de Desenvolvimento Institucional & 05 \\
2 & $\begin{array}{l}\text { Perspectiva científica e pedagógica formadora: políticas, normas e } \\
\text { estímulos para o ensino, a pesquisa e a extensão }\end{array}$ & 30 \\
3 & Responsabilidade social da IES & 10 \\
4 & Comunicação com a sociedade & 05 \\
5 & Políticas de pessoal, de carreira, de aperfeiçoamento, de condições de & 20 \\
7 & trabalho & 05 \\
8 & Organização e gestão da instituição & 10 \\
9 & Infra-estrutura física e recursos de apoio & 05 \\
10 & Planejamento e avaliação & 05 \\
\hline
\end{tabular}

Fonte: Brasil (2005, p. 23).

Cada dimensão apresenta indicadores organizados em grupos segundo a idéia de atribuir um conceito específico para cada elemento que evidencia o padrão de qualidade institucional. Os grupos agregam as características comuns para reunir os indicadores de forma lógica. Cada indicador exprime um aspecto ou uma característica específica da instituição, que podem ser observados, medidos, qualificados ou analisados. Alguns indicadores são considerados imprescindíveis pelo Sinaes, ou seja, representam condições obrigatórias definidas pela legislação em vigor para o acesso e a permanência da instituição no sistema de ensino superior, segundo três categorias possíveis: Universidade, Centro Universitário e Faculdade.

De acordo com a legislação brasileira, a avaliação de cursos, instituições e estudantes da educação superior deve adotar a escala de conceitos de 1 a 5, estabelecendo a seguinte classificação: conceitos 1 e 2 situação ou desempenho fracos; conceito 3 - mínimo aceitável; conceitos 4 e 5 - situação ou desempenho fortes. Os conceitos devem explicitar elementos que além de estar presentes na realidade do cotidiano das IES, 
exprimam também se há intencionalidade, direcionamento e compartilhamento que demonstrem a existência de uma construção coletiva e de uma progressiva institucionalização do conjunto de projetos e práticas constitutivas da identidade institucional. Para tanto, cabe ao avaliador externo observar os seguintes aspectos: "freqüência e intensidade de práticas e políticas acadêmicas; institucionalização decorrente da interação entre políticas e práticas institucionais; participação e apropriação pelos atores (internos e externos) das políticas e de seus resultados" (Brasil, 2005, p. 24).

O conceito final atribuído a cada uma das dimensões do Sinaes é calculado em duas etapas: 1) cálculo automático da média aritmética dos conceitos pertinentes àquela dimensão, feito por programa de computador; 2) transformação da média aritmética em um conceito na escala do Sinaes por meio de aproximações realizadas com a interferência dos avaliadores. Essa interferência ocorre quando a média aritmética dos indicadores se encontra em pontos intermediários entre dois valores inteiros (decimais 0,4 e 0,7), para minimizar erros de aproximação feitos pelos programas computacionais e melhorar a qualidade do processo de atribuição de conceitos. A transformação da média aritmética dos indicadores em conceitos é realizada segundo a matriz de associação apresentada no quadro 2.

\section{Quadro 2 - Matriz de associação para atribuição de conceitos às dimensões do Sinaes}

\begin{tabular}{|c|c|}
\hline $\begin{array}{c}\text { Média Aritmética dos Indicadores da } \\
\text { Dimensão (MAI) }\end{array}$ & Conceito da Dimensão \\
\hline $1,0 \leq \mathrm{MAI}<1,4$ & 1 \\
$1,4 \leq \mathrm{MAI} \leq 1,7$ & 1 ou 2, a critério dos avaliadores \\
$1,7<\mathrm{MAI}<2,4$ & 2 \\
$2,4 \leq \mathrm{MAI} \leq 2,7$ & 2 ou 3, a critério dos avaliadores \\
$2,7<\mathrm{MAI}<3,4$ & 3 \\
$3,4 \leq \mathrm{MAI} \leq 3,7$ & 3 ou 4, a critério dos avaliadores \\
$3,7<\mathrm{MAI}<4,4$ & 4 \\
$4,4 \leq \mathrm{MAI} \leq 4,7$ & 4 ou 5, a critério dos avaliadores \\
$4,7<\mathrm{MAI}<5,0$ & 5 \\
\hline
\end{tabular}

Fonte: Brasil (2005, p. 21). 
A atribuição do conceito final da avaliação externa para as IES em escala de 1 a 5 resulta da média ponderada das médias aritméticas, segundo os pesos das dimensões descritos anteriormente. A transformação da média ponderada em conceitos ocorre por meio de aproximações realizadas com a interferência dos avaliadores, que utilizam sempre o modelo das matrizes de associação. Após a atribuição de um conceito global, o avaliador apresenta uma análise geral e conclusiva, com a finalidade de identificar as potencialidades e fragilidades da instituição avaliada e a proposição de recomendações com vistas à melhoria da sua qualidade.

O quadro 3 apresenta os indicadores de qualidade da dimensão 5, que possui o segundo maior peso relativo de todo o sistema de avaliação, onde aparece o grupo TRP (Titulação, Regime de Trabalho e Publicações do Corpo Docente), que interessa destacar aqui.

Quadro 3-Indicadores da dimensão 5 do Sinaes: as políticas de pessoal, de carreiras do corpo docente e corpo técnico administrativo, seu aperfeiçoamento, desenvolvimento profissional e suas condições de trabalho

\begin{tabular}{|l|l|}
\hline \multicolumn{1}{|c|}{ Grupos de Indicadores } & \multicolumn{1}{c|}{ Indicadores de Qualidade } \\
\hline Perfil docente & $\begin{array}{l}\text { Titulação (Indicador imprescindível para universidades e centros } \\
\text { universitários) } \\
\text { Publicações e produções } \\
\text { Regime de trabalho (Indicador imprescindível para universidades } \\
\text { Condições Institucionais para os docentes } \\
\text { Plano de carreira (Indicador imprescindível) }\end{array}$ \\
$\begin{array}{l}\text { Corpo técnico-administrativo e as condições } \\
\text { institucionais }\end{array}$ & $\begin{array}{l}\text { Políticas de capacitação e de acompanhamento do trabalho } \\
\text { docente e formas de sua operacionalização } \\
\text { Perfil técnico-administrativo (formação e experiência) } \\
\text { Plano de carreira e capacitação do corpo técnico-administrativo }\end{array}$ \\
\hline
\end{tabular}

Fonte: Brasil (2005, p. 40).

\section{CONSIDERAÇÕES SOBRE A CONSISTÊNCIA DO TRP}

A atribuição de conceitos para os indicadores do grupo TRP foram automatizados pelo Sinaes, a fim de subsidiar o trabalho dos avaliadores (Brasil, 2005, p. 82-98). O cálculo proposto, no entanto, pode ser facilmente 
questionado quanto à consistência dos resultados que ele produz, como será visto na discussão dos itens a seguir.

\section{1) Titulação}

A titulação do corpo docente é um indicador imprescindível para universidades e centros universitários, sendo calculado a partir de uma fórmula que define o parâmetro MT, correspondente a um tipo de média ponderada que envolve o número de doutores, mestres, especialistas e graduados, atribuindo-se a cada categoria um peso que define graus de importância distintos aos títulos correspondentes. Tem-se que: $M T=\frac{P_{E} \times N_{E}+P_{M} \times N_{M}+P_{D} \times N_{D}}{D}$, onde: $P_{E}$ é o peso da especialização -

10; $N_{E}$ é o número de docentes com especialização; $P_{M}$ é o peso do mestrado - 30; $N_{M}$ é o número de docentes com mestrado; $P_{D}$ é o peso do doutorado - 60; $N_{D}$ é o número de docentes com doutorado; $D$ é o total dos docentes da instituição (graduados + especialistas + mestres + doutores).

Considerando-se a exigência mínima para a titulação do corpo docente, a fórmula é aplicada para estabelecer as faixas de valores dos conceitos do indicador, conforme a matriz de associação apresentada no quadro a seguir.

\section{Quadro 4 - Matriz de associação para atribuição de conceitos à titulação do corpo docente}

\begin{tabular}{|cccc|}
\hline $\begin{array}{c}\text { Conceito do } \\
\text { Indicador }\end{array}$ & $\begin{array}{c}\text { Faixa de Valores para as } \\
\text { Universidades }\end{array}$ & $\begin{array}{c}\text { Faixa de Valores para os } \\
\text { Centros Universitários }\end{array}$ & $\begin{array}{c}\text { Faixa de Valores para as } \\
\text { Faculdades }\end{array}$ \\
\hline 1 & $0 \leq \mathrm{MT}<13$ & $0 \leq \mathrm{MT}<12$ & $0 \leq \mathrm{MT}<11$ \\
2 & $13 \leq \mathrm{MT}<16,60$ & $12 \leq \mathrm{MT}<14$ & $11 \leq \mathrm{MT}<12$ \\
3 & $16,60 \leq \mathrm{MT}<20$ & $14 \leq \mathrm{MT}<16,6$ & $12 \leq \mathrm{MT}<14$ \\
4 & $20 \leq \mathrm{MT}<25$ & $16,6 \leq \mathrm{MT}<20$ & $14 \leq \mathrm{MT}<16$ \\
$\mathbf{5}$ & $25 \leq \mathrm{MT}$ & $20 \leq \mathrm{MT}$ & $16 \leq \mathrm{MT}$ \\
\hline
\end{tabular}

Fonte: Brasil (2005, p. 84, 86, 87).

Diante dos dados do corpo docente da instituição, o avaliador externo calcula o valor do parâmetro MT pela fórmula, e atribui um conceito final para a titulação, conforme as faixas dessa matriz de 
associação. $\mathrm{O}$ fato de se estar trabalhando com faixas de valores baseadas em exigências mínimas para a titulação do corpo docente torna justificável que um mesmo conceito possa ser atribuído a instituições com diferentes proporções de doutores, mestres, especialistas e graduados em seus quadros. No entanto, o processo de cálculo deveria apresentar maior consistência em relação a tais proporções, pois suponha uma instituição genérica em que todos os docentes tenham o título de mestre, condição em que as variáveis da fórmula para o cálculo de $M T$ valeriam: $N_{E}=0, N_{M}=D$, $N_{D}=0$. Logo: $M T=\frac{10 \times 0+30 \times D+60 \times 0}{D}=30$, de forma que, pela matriz de associação, o conceito da titulação dessa instituição seria igual a 5 .

Supondo, agora, outra instituição em que todos os docentes sejam doutores. Tem-se: $N_{E}=0, \quad N_{M}=0, N_{D}=D$. Logo: $M T=\frac{10 \times 0+30 \times 0+60 \times D}{D}=60 ;$ desse modo, o conceito da titulação para essa instituição, a exemplo da anterior, também seria igual a 5 .

Em razão desses resultados, pergunta-se: o conceito do indicador que exprime a titulação para uma IES em que todos os docentes de seu quadro são doutores não deveria ser maior do que quando todos os docentes são mestres? É razoável supor que a resposta seja sim, mas, por outro lado, pode-se justificar o fato do conceito ser o mesmo porque o cálculo se baseia em exigências mínimas para a titulação. Na legislação brasileira, a exigência para centros universitários é possuir percentual mínimo de $20 \%$ do corpo docente com titulação acadêmica de mestrado ou de doutorado. No caso das universidades essa exigência corresponde a um terço.

Considerando uma instituição genérica que apresente em seu quadro docente exatamente um terço de mestres, e o restante formado por especialistas. Nesse caso, tem-se: $N_{E}=\frac{2 D}{3}, N_{M}=\frac{D}{3}, N_{D}=0$. Logo, $M T=\frac{\frac{2 D}{3} \times 10+\frac{D}{3} \times 30+0 \times 60}{D}=16,66$. Portanto, pela matriz de associação, o conceito dessa instituição para a titulação seria igual a 3, se ela fosse uma universidade, e igual a 4 se ela fosse um centro universitário. 
Imaginemos, agora, outra instituição genérica em que seu quadro docente seja formado por exatamente um terço de doutores, e o restante por especialistas. Nesse caso, tem-se: $N_{E}=\frac{2 D}{3}, N_{M}=0, N_{D}=\frac{D}{3}$. Logo, $M T=\frac{\frac{2 D}{3} \times 10+30 \times 0+\frac{D}{3} \times 60}{D}=26,66$. Portanto, o conceito dessa instituição para a titulação seria igual a 5, tanto se ela fosse uma universidade quanto um centro universitário.

Com esses exemplos, vê-se que a proporção da titulação dentro da exigência mínima não constitui um critério preciso, pois quando todos os docentes são mestres ou doutores, o conceito é o mesmo, tanto para as universidades quanto para os centros universitários; porém, quando o quadro docente passa de um terço de mestres para um terço de doutores, sem variar o número de especialistas, há a diferença de um ponto na escala conceitual entre ambas as categorias administrativas. Pode-se inferir que o cálculo proposto pelo Sinaes precisa ser revisto, para contemplar esta e outras situações que suscitam resultados questionáveis à atribuição de conceitos para a titulação do corpo docente.

\section{2) Regime de Trabalho}

O regime de trabalho também é um indicador imprescindível para universidades e centros universitários, sendo calculado pelo Sinaes a partir de uma fórmula que define o parâmetro $R T$, correspondente a um tipo de média ponderada que envolve o número de docentes nos regimes integral, parcial e horista, atribuindo-se a cada categoria um peso que define graus de importância distintos. Tem-se que: $R T=\frac{P_{I} \times N_{I}+P_{P} \times N_{P}+P_{H} \times N_{H}}{D}$, onde: $P_{I}$ é o peso do regime integral $-60 ; N_{I}$ é o número de docentes em regime integral; $P_{P}$ é o peso do regime parcial $-30 ; N_{P}$ é o número de docentes em regime parcial; $P_{H}$ é o peso do regime horista $-10 ; N_{H}$ é o número de docentes em regime horista; $D$ é o número de docentes da instituição.

Diante dos dados institucionais, o avaliador externo utiliza a fórmula e chega a um valor que deverá ser convertido no indicador do regime de trabalho da instituição, conforme as faixas de valores da matriz de associação apresentada no quadro 5. 


\section{Quadro 5 - Matriz de associação para atribuição de conceitos ao regime de trabalho do corpo docente}

\begin{tabular}{|cccc|}
\hline $\begin{array}{c}\text { Conceito do } \\
\text { Indicador }\end{array}$ & $\begin{array}{c}\text { Faixa de Valores para as } \\
\text { Universidades }\end{array}$ & $\begin{array}{c}\text { Faixa de Valores para os } \\
\text { Centros Universitários }\end{array}$ & $\begin{array}{c}\text { Faixa de Valores para as } \\
\text { Faculdades }\end{array}$ \\
\hline 1 & $0 \leq \mathrm{RT}<17,5$ & $0 \leq \mathrm{RT}<15$ & $0 \leq \mathrm{RT}<12,5$ \\
2 & $17,5 \leq \mathrm{RT}<26,5$ & $15 \leq \mathrm{RT}<20$ & $12,5 \leq \mathrm{RT}<15$ \\
3 & $26,5 \leq \mathrm{RT}<35$ & $20 \leq \mathrm{RT}<25$ & $15 \leq \mathrm{RT}<17,5$ \\
4 & $35,0 \leq \mathrm{RT}<40$ & $25 \leq \mathrm{RT}<30$ & $17,5 \leq \mathrm{RT}<22,5$ \\
$\mathbf{5}$ & $40 \leq \mathrm{RT}$ & $30 \leq \mathrm{RT}$ & $22,5 \leq \mathrm{RT}$ \\
\hline
\end{tabular}

Fonte: Brasil (2005, p. 89, 90, 92).

Os problemas que decorrem do processo de cálculo para o indicador "regime de trabalho" são semelhantes aos já mostrados no caso da titulação. Suponha uma instituição genérica em que todos os docentes trabalhem em regime integral, condição em que as variáveis da fórmula para o cálculo de $R T$ valem: $N_{I}=D, N_{P}=0, N_{H}=0$. Logo: $R T=\frac{60 \times D+30 \times 0+10 \times 0}{D}=60$; portanto, pela matriz de associação, o conceito da titulação dessa instituição seria igual a 5, seja ela uma universidade, um centro universitário ou uma faculdade.

Considerando, agora, outra instituição genérica em que apenas a metade de seu corpo docente trabalha em regime integral, encontrando-se as outras duas categorias divididas em um quarto cada uma. Nessas condições, o valor do parâmetro $R T$ será o seguinte: $R T=\frac{60 \times \frac{D}{2}+30 \times \frac{D}{4}+10 \times \frac{D}{4}}{D}=40$, de modo que, pela matriz de associação, o conceito do indicador para o regime de trabalho dessa instituição também seria igual a 5, seja qual for sua categoria administrativa.

Diante desses resultados, pergunta-se: o conceito do indicador que exprime o regime de trabalho para uma IES, em que todos os docentes trabalham em período integral, não deveria ser maior caso houvesse apenas a metade nessa condição, e a outra metade dividida igualmente entre as demais categorias possíveis? A resposta mais razoável deveria ser positiva, mas novamente surge o argumento de que na legislação brasileira há uma exigência mínima relacionada ao regime de trabalho, o que justificaria o 
fato de instituições bastante diferentes nesse quesito receberem o mesmo conceito. Mas, se forem mantidas proporções próximas entre as classes de regime de trabalho, verifica-se que a atribuição dos conceitos pode variar bastante. Por exemplo: fazendo-se o cálculo para instituições em que metade menos 1 do corpo docente trabalha em regime integral e metade mais 1 em regime horista, chega-se a conceitos iguais a 1 para as universidades, 2 para os centros universitários e 3 para as faculdades. Já no caso do cálculo feito acima para a metade do corpo docente trabalhando em regime integral, um quarto como parcial e um quarto como horista, chegase a um conceito igual a 5 para todas as categorias administrativas. Como se vê, a redução de apenas um quarto no número de docentes horistas, transformando-os em regime parcial, sem alterar praticamente quase nada do regime de carga integral, faz uma diferença enorme nesse caso. Assim, conclui-se que o cálculo proposto pelo Sinaes para o indicador do regime de trabalho precisa ser revisto, evitando as dificuldades aqui levantadas.

\section{3) Publicações e Produções do Corpo Docente}

Mesmo que não seja considerado um indicador imprescindível para os cursos de graduação de que trata o Sinaes, as publicações e produções abrangem uma extensa quantidade de itens importantíssimos para as instituições, pois correspondem aos produtos finais acabados, decorrentes das atividades científica, técnica e artística que subsidiam o processo didático-pedagógico. A fórmula a seguir transcrita estabelece para esse indicador um parâmetro $N$, correspondente a um tipo de média ponderada do número de artigos científicos, livros e capítulos, trabalhos completos e resumos em anais, projetos técnicos e produções artísticas, segundo pesos que definem graus relativos de importância para cada categoria. Tem-se que:

$$
N=\frac{P_{A} \times n_{a}+P_{L} \times n_{l}+P_{T} \times n_{t}+P_{R} \times n_{r}+P_{P I} \times n_{p i}+P_{P T} \times n_{p t}+P_{D P} \times n_{d p}}{\left(P_{A}+P_{L}+P_{T}+P_{R}+P_{P I}+P_{P T}+P_{D P}\right) \times D},
$$

onde: $P_{A}$ é o peso atribuído aos artigos dos periódicos científicos indexados - 30; $n_{a}$ é o número de artigos publicados pelo corpo docente nos últimos três anos em periódicos científicos indexados; $P_{L}$ é o peso atribuído aos livros ou capítulos de livros - 20; $n_{l}$ é o número de livros ou capítulos publicados pelo corpo docente nos últimos três anos; $P_{T}$ é o peso atribuído aos trabalhos publicados em anais - $10 ; n_{t}$ é o número de trabalhos publicados em anais pelo corpo docente nos últimos três anos; $P_{R}$ é o peso atribuído aos resumos publicados em anais $-05 ; n_{r}$ é o número de resumos publicados em anais pelo corpo docente nos últimos três anos; $P_{P I}$ é o peso atribuído às propriedades intelectuais depositadas ou registradas $-15 ; n_{p i}$ é 
o número de propriedades intelectuais depositadas ou registradas pelo corpo docente nos últimos três anos; $P_{P T}$ é o peso atribuído aos projetos ou produções artísticas, técnicas, culturais ou científicas - 10; $n_{p t}$ é o número de projetos ou produções artísticas, técnicas, culturais e científicas do corpo docente da instituição nos últimos três anos; $P_{D P}$ é o peso atribuído às produções didático-pedagógicas relevantes - 10; $n_{d p}$ é o número de produções didático-pedagógicas relevantes do corpo docente nos últimos três anos; $D$ é o número total de docentes da instituição.

Partindo da média aritmética dos pesos de cada um dos tipos de publicações e produções, o Sinaes estabelece as faixas para esse indicador, conforme os valores de $\mathrm{N}$ mostrados na matriz de associação do quadro 6 .

\section{Quadro 6 - Matriz de associação para atribuição de conceitos às publicações e produções do corpo docente}

\begin{tabular}{|cccc|}
\hline $\begin{array}{c}\text { Conceito do } \\
\text { Indicador }\end{array}$ & $\begin{array}{c}\text { Faixa de Valores para as } \\
\text { Universidades }\end{array}$ & $\begin{array}{c}\text { Faixa de Valores para os } \\
\text { Centros Universitários }\end{array}$ & $\begin{array}{c}\text { Faixa de Valores para as } \\
\text { Faculdades }\end{array}$ \\
\hline 1 & $0 \leq \mathrm{N}<0,007145$ & $0 \leq \mathrm{N}<0,00429$ & $0 \leq \mathrm{N}<0,0021435$ \\
2 & $0,007145 \leq \mathrm{N}<0,012861$ & $0,00429 \leq \mathrm{N}<0,007145$ & $0,0021435 \leq \mathrm{N}<0,00429$ \\
3 & $0,012861 \leq \mathrm{N}<0,1429$ & $0,007145 \leq \mathrm{N}<0,07145$ & $0,00429 \leq \mathrm{N}<0,0429$ \\
4 & $0,1429 \leq \mathrm{N}<0,2858$ & $0,07145 \leq \mathrm{N}<0,1429$ & $0,0429 \leq \mathrm{N}<0,08574$ \\
$\mathbf{5}$ & $0,2858 \leq \mathrm{N}$ & $0,1429 \leq \mathrm{N}$ & $0,08574 \leq \mathrm{N}$ \\
\hline
\end{tabular}

Fonte: Brasil (2005, p. 94, 96, 98).

Dentre todos os sistemas de cálculo de conceitos apresentados pelo Sinaes para a avaliação externa, o indicador das publicações e produções do corpo docente é o mais consistente, pois as faixas da sua matriz de associação não fornecem resultados tão facilmente questionáveis, como no caso dos dois indicadores anteriores. Mas não se pode deixar de considerar a diferença entre os padrões de qualidade dos veículos de publicação ou dos meios de divulgação da produção docente, o que não é contemplado pelo sistema de cálculo proposto pelo Sinaes. Para efeito da avaliação, no âmbito da pós-graduação no Brasil, foi desenvolvido o sistema Qualis, resultado do processo de classificação dos periódicos científicos, nacionais e estrangeiros, utilizados pelos programas de pós-graduação para a divulgação da produção intelectual de seus docentes e alunos. Os periódicos são classificados dentro das áreas de conhecimento em três 
categorias, baseadas nos critérios pertinentes à abrangência de sua circulação: Local, Nacional e Internacional. Em cada categoria de circulação há três níveis de qualidade, designados pelas letras $\mathrm{A}, \mathrm{B}$ e $\mathrm{C}$, de forma a estabelecer uma escala de 9 pontos que vai desde o nível Local $C$, para os periódicos de menor qualidade, até o nível Internacional A, para os de maior prestígio acadêmico. Com isso, o sistema de avaliação da pósgraduação elimina as ambigüidades que ocorrem em relação à qualidade do material publicado nos periódicos científicos pelos professores e alunos. No sistema de cálculo do Sinaes, pode ocorrer que uma instituição cujos docentes publicaram nos últimos três anos, em periódicos de circulação local, em maior quantidade, receba um conceito maior do que outra instituição cujos docentes publicaram, no mesmo período, em menor quantidade, porém em revistas de nível internacional. Assim, o Sinaes poderá, em breve, adotar a escala Qualis de nove pontos já existente, aperfeiçoando o seu sistema de cálculo.

\section{CONSIDERAÇÕES FINAIS}

A avaliação externa da educação superior no Brasil alcançou nos últimos anos níveis de excelência semelhantes aos verificados nos países que apresentam graus elevados de prestação de contas no setor. As informações provindas desses países mostram que a expansão quantitativa desse nível de ensino foi realizada mediante um rígido e sistemático controle dos padrões de qualidade, obedecendo a processos de avaliação sujeitos a constantes aperfeiçoamentos. As diretrizes e os instrumentos metodológicos patrocinados pelo Sinaes, mesmo que se destaquem mais pelos seus avanços do que pelos problemas que eventualmente se traduzem em defeitos, necessitam ser melhorados em alguns pontos já previstos pelo próprio Sinaes e também pela literatura especializada. O aperfeiçoamento da base de dados do Sinaes permitirá comparar, de maneira mais coerente, os resultados dos padrões de qualidade encontrados, evitando que os cálculos baseados em fórmulas que simplificam demais o processo de atribuição de conceitos, como acontece com o grupo de indicadores TRP, não consigam exprimir objetivamente as melhorias implementadas pelas instituições. 


\section{REFERÊNCIAS BIBLIOGRÁFICAS}

ALFAN, E.; OTHMAN, M. N. Undergraduate students' performance: the case of University of Malaya. Quality Assurance in Education, v. 13, n. 4, p. 329-343, 2005.

AMORIM, A. Avaliação Institucional da Universidade. São Paulo: Cortez, 1991.

BRASIL. Decreto n. 2.026, de 10 de outubro de 1996. Estabelece procedimentos para o processo de avaliação dos cursos e instituições de ensino superior. Diário Oficial, Poder Executivo, Brasília, DF, 11 out. 1996. Seção I.

. Lei n. 10.172, de 9 de janeiro de 2001. Aprova o Plano Nacional de Educação e dá outras providências. 2001a. Disponível em: <http://www. adunesp.org.br/download/PNE\%20-\%20Lei\%2010172-\%2009-01-01.pdf>. Acesso em: 15 maio 2007.

Decreto n. 3.860, de 09 de julho de 2001. Dispõe sobre a organização do ensino superior, a avaliação de cursos e instituições, e dá outras providências. 2001b. Disponível em: <http://www.ead.ufsc.br /profor/disciplinas/textos/texto008.pdf>. Acesso em: 15 maio 2007.

Lei n. 10.861, de 14 de abril de 2004. Institui o Sistema Nacional de Avaliação da Educação Superior - Sinaes e dá outras providências. 2004a. Disponível em: <http://www.mec.gov.br/legis/pdf/110861.pdf>. Acesso em: 15 maio 2004.

Portaria n. 2.051, de 9 de julho de 2004. Regulamenta os procedimentos de avaliação do Sistema Nacional de Avaliação da Educação Superior (Sinaes), instituído na Lei n. 10.861, de 14 de abril de 2004. Diário Oficial, Poder Executivo. Brasília, n. 132, p. 12, 2004b. Seção I.

Ministério da Educação. Secretaria de Ensino Superior. Comissão para a reformulação da Educação Superior. Uma nova política para a Educação Superior. Brasília: MEC, 1985.

- Instituto Nacional de Estudos e Pesquisas Educacionais Anísio Teixeira (Inep). Diretoria de Estatísticas e Avaliação da Educação Superior. Censo da Educação Superior - 2003: resumo técnico. Brasília: MEC, 2004.

- Comissão Nacional de Avaliação da Educação Superior (Conaes)/Instituto Nacional de Estudos e Pesquisas Educacionais Anísio Teixeira (Inep). Avaliação externa de instituições de educação superior: diretrizes e instrumento. Brasília: MEC, 2005. 
CUNHA, L. A. Nova reforma do ensino superior: a lógica reconstruída. Cadernos de Pesquisa, n. 101, p. 20-49, 1997.

DIAS, C. L. Avaliação da capacitação pedagógica do docente de ensino superior através de uma escala de atitudes. Marília, 2001. 262f. Tese (dout.). Universidade Estadual Paulista.

ENCONTRO Internacional de Avaliação do Ensino Superior. Anais... Brasília: MEC/SESu, 1988.

GOMES, A. M. Política de avaliação da educação superior: controle e massificação. Educação $\mathcal{E}$ Sociedade. Campinas, v. 23, n. 80, p. 275-298, set. 2002.

GONÇALVES FILHO, F. Enfoques avaliativos em revista: concepções de avaliação institucional em questão. Política da Educação Superior - GT 11. Brasília: FE-Unicamp/Capes. 2004. Disponível em: <http://www.anped. org.br/25/posteres/francisco goncalvesfilhop11.rtf $>$. Acesso em: 15 maio 2007.

GREGO, S. M. D.; SOUZA, C. B. G. A Normatização da avaliação institucional das instituições universitárias na instância federal e no governo do Estado de São Paulo e a autonomia universitária. 2004. Disponível em: <http:/ /www.anped. org.br/26/trabalhos/soniamariaduartegrego.rtf $>$. Acesso em: 15 maio 2007.

HARVEY, L. A History and critique of quality evaluation in the UK. Quality Assurance in Education, v. 13, n. 4, p. 263-276, 2005.

LEITE, D. B. C. Avaliação e tensões de estado, universidade e sociedade na América Latina. Avaliação: Revista da Rede de Avaliação Institucional da Educação Superior - RAIES. Campinas: Unicamp, ano 2, v.2, n. 1, mar. 1997.

LEMAITRE, M. J. Development of external quality assurance schemes: an answer to the challenges of higher education evolution. Quality in Higher Education, v. 10, n. 2, p. 89-99, 2004.

MOK, K. The quest for world class university: quality assurance and international benchmarking in Hong Kong. Quality Assurance in Education, v. 13, n. 4, p. 277-304, 2005.

NEIVA, C. C. Avaliação do Ensino Superior: relato de uma experiência. Brasília, nov. 1988. 17p. Documento interno da Assessoria do SESu/MEC. 
NGUYEN, D. N.; YOSHINARI, Y.; SHIGEJI, M. University education and employment in Japan: students' perceptions on employment attributes and implications for university education. Quality Assurance in Education, v. 13, n. 3, p. 202-218, 2005.

ROMANELLI, O. L. História da Educação no Brasil (1930/1973). Petrópolis: Vozes, 1978.

ROZSNYAI, C. A Decade of accreditation in Hungary: lessons learned and future directions. Quality in Higher Education, v. 10, n. 2, p. 129-138, 2004.

SGUISSARDI, V. Para avaliar propostas de avaliação do ensino superior. In: SGUISSARDI, V. (org.). Avaliação Universitária em questão: reformas do Estado e da educação superior. Campinas: Autores Associados, 1997.

SILVA, E. M. C.; LOURENÇO, E. B. Avaliação institucional no Brasil: contexto e perspectiva. Avaliação, v. 3, n. 4, p. 63-73, dez. 1998.

SOBRINHO, J. D. Avaliação institucional: marcos teóricos e políticos. Avaliação, v.1, n.1, p.15-24, jul. 1996.

- Avaliação institucional da educação superior: fontes externas e internas. Avaliação, v. 3, n. 4, p. 29-35, dez. 1998.

STELLA, A. External quality assurance in Indian Higher Education: developments of a decade. Quality in Higher Education, v. 10. n. 2, p. 115$127,2004$.

STRYDOM, A. H.; STRYDOM, J. F. Establishing Quality Assurance in the South African Context. Quality in Higher Education, v. 10, n. 2, p. 101-113, 2004.

VIANNA, H. M. Questões de avaliação educacional: proposta para discussão. Avaliação: construindo o campo e a crítica. Florianópolis (SC): Insular, 2002.

Recebido em: janeiro 2007

Aprovado para publicação em: abril 2007 
